\title{
NONDESTRUCTIVE 2-D GEOELECTRICAL SURVEYING INTO A BUILDING'S BASEMENT
}

\author{
Athanasiou E. ${ }^{1}$, Tsourlos P. ${ }^{1}$, Vargemezis G. ${ }^{1}$, and Tsokas G. ${ }^{1}$ \\ ${ }^{1}$ Aristotle University of Thessaloniki, School of Geology, Department of Geophysics, \\ athanael@geo.auth.gr,varge@geo.auth.gr,tsourlos@geo.auth.gr
}

\begin{abstract}
In this paper the application of flat base electrodes into a building's basement is examined. The aim of this study was to locate ancient walls possibly situated underneath a building, lying on Ag. Dimitriou road in Thessaloniki (Greece). During ERT surveying, an archaeological excavation took place on the roadway outside the building. The excavation revealed ancient walls. A number of resistivity profiles were carried out on the concrete floor of the building. The dipole-dipole array was used in some sections, while in others the Wenner array was undertaken. The spacing " $a$ " between electrodes was $1 m$ and the maximum $N$-separation of $N_{\max }=8$. In order to perform resistivity profiles in a nondestructive manner on the concrete floor, flat base electrodes were applied. The resistivity surveying indicated the existence of linear structures identified as resistive bodies. These anomalies may have been derived from various causes, but most likely they may have been derived from the continuation of the ancient walls revealed from the archaeological excavation on the roadway. Finally, it must be noted that flat base electrodes proved to be an efficient tool for measuring indoors.
\end{abstract}

Key words: Flat base electrodes, contact electrodes, nondestructive ERT.

\section{Пврі́іпчи}

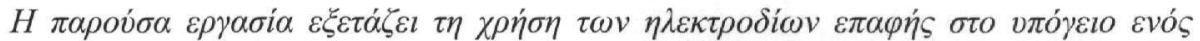

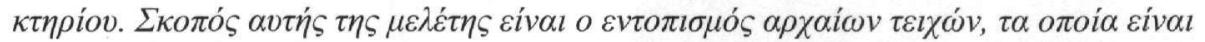

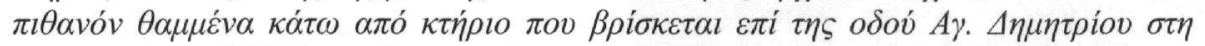

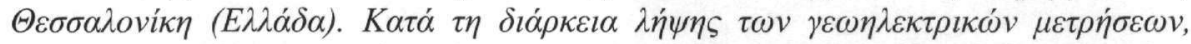

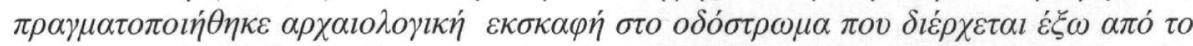

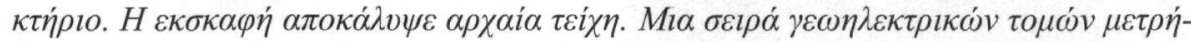

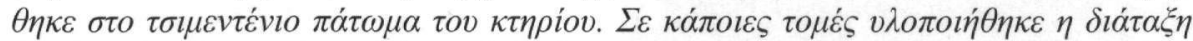

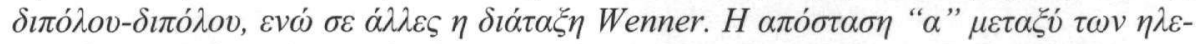

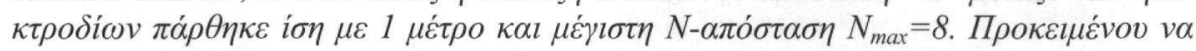

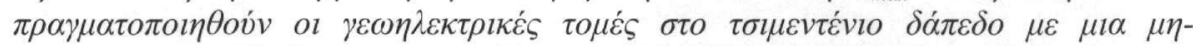

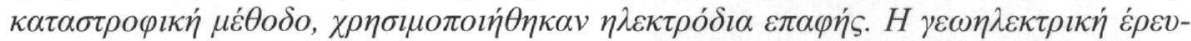

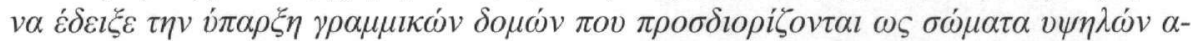

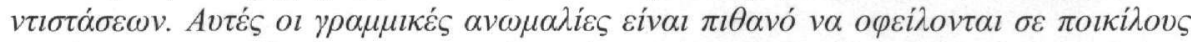

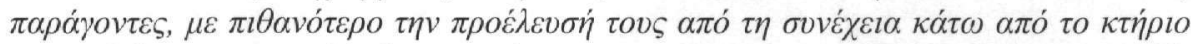

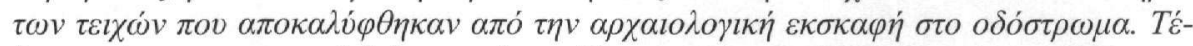

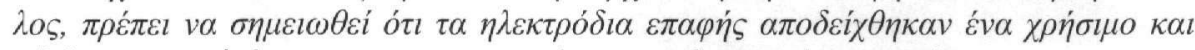

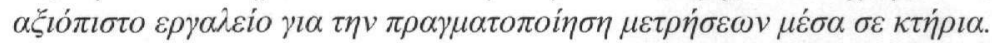

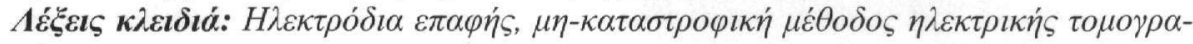
pias. 


\section{Introduction}

Over the last decade, Electrical Resistivity Tomography (ERT) has been extensively used in geophysical investigations (Dahlin 2001). The most common applications of ERT are geological mapping (Caglar and Duvarci 2001), geothermal field exploration (Wright et al. 1985) hydrogeological studies (Flathe 1955, Dahlin and Owen 1998), engineering geology studies (Dahlin et al. 1994), environmental research (Rogers and Kean 1980, Van et al. 1991, Ramirez, et al. 1996) and archaeological prospection (Papadopoulos et al. 2006).

The rapid development of civil centers and various constructions resulted in the need to use geophysical techniques in urban environments (indoors, paved surfaces, roads, etc.) Among the existing geophysical techniques the method of GPR is highly popular (Daniels 2004) due to its fully non-destructive nature and survey speed. Further, the introduction of the newly developed technique of capacitive resistivity (Kuras 2002) holds the promise of efficient electrical imaging in areas where no (or poor) galvanic contact is possible, but its use is mainly restricted to map the shallow subsurface.

As far as standard geoelectrical methods concerns, new techniques have been developed recently, such as flat base electrodes, which allow resistivity measurements to be made in a nondestructive manner and, therefore extend the application of ERT to other environments (e.g. urban, indoors, etc.). Carrara et al. (2001), demonstrate the application of geoelectrical measurements using flat base electrodes on a mosaic floor of a Roman residence. The application of non-destructive geoelectrical grid to access wall structures is presented by Cosentino and Martorana (2001), while Karastathis et al. (2002) applied non-destructive ERT measurements on a cement dam in Marathon (Greece).
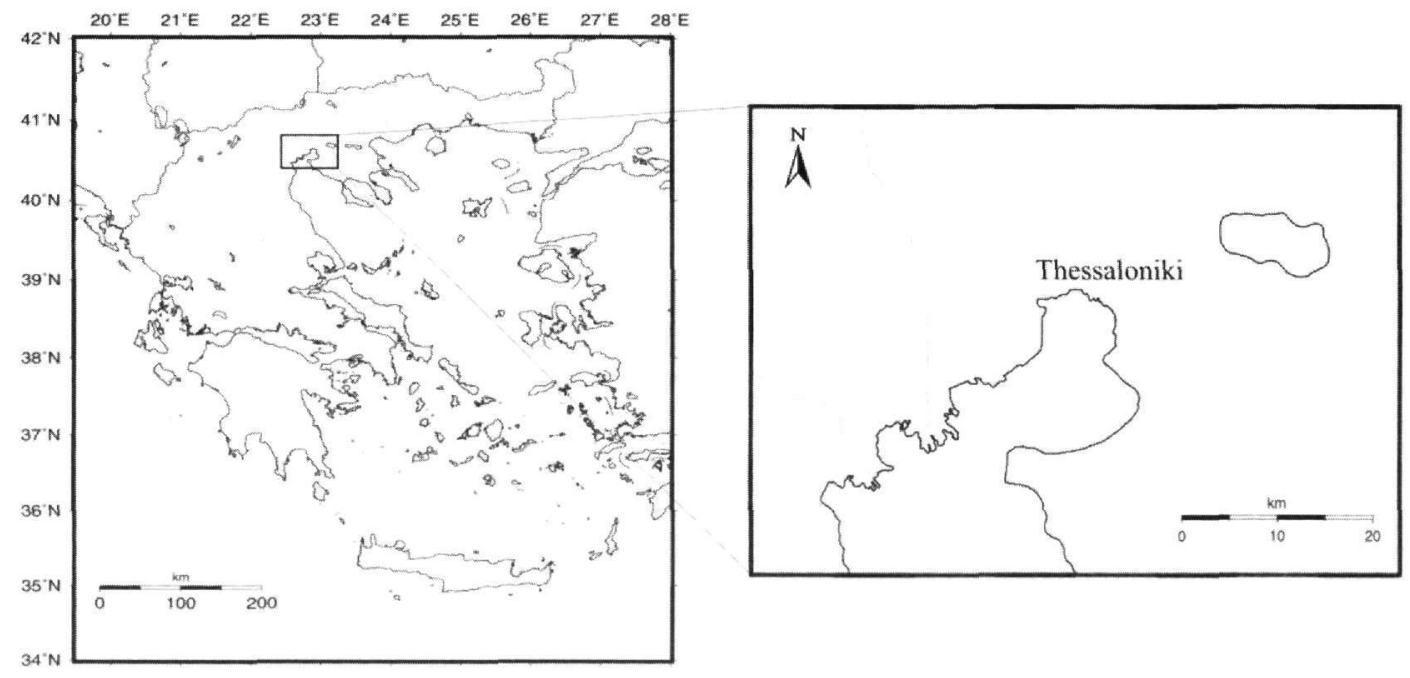

Figure 1 - Location map of the studying area

This work focuses on an application of flat base electrodes on a concrete floor of a building's basement. The aim of this study was to locate ancient walls possibly situated underneath a building, lying on Ag. Dimitriou road in Thessaloniki (Fig. 1). During ERT surveying, an archaeological excavation took place on the roadway outside the building (Fig. 2). The excavation revealed ancient walls. The question was if these walls continued underneath the studying building, situated next to the roadway, or not. 


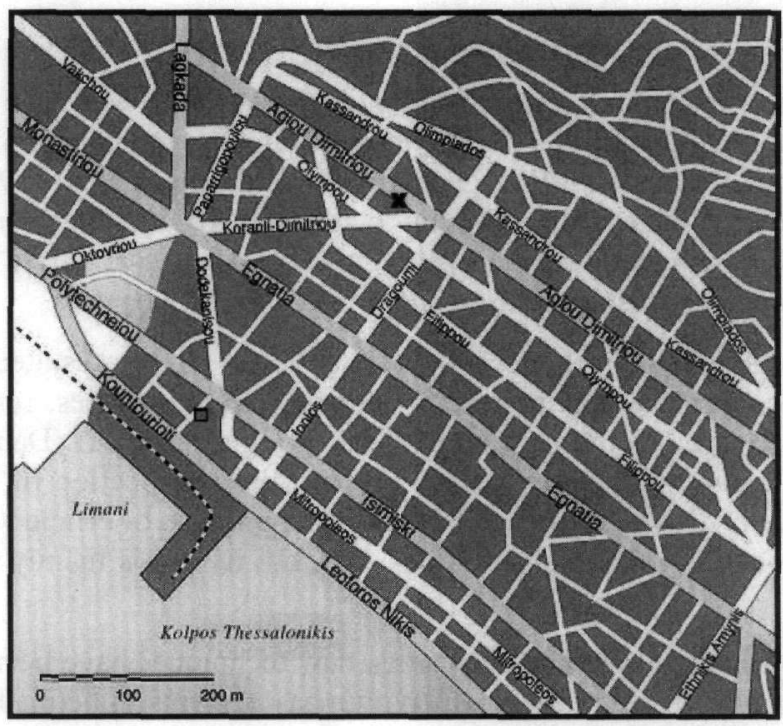

Figure 2 - Topographical sketch of the studying area. The building is depicted with a cross

\section{Geological Setting}

The area of Thessaloniki (Fig. 3) belongs to the Circum Rhodope belt (Kauffmann et al. 1976, Ricou et al. 1998), which consists of Paleozoic and Mesozoic metamorphic rocks covered by cenozoic metasedimentary rocks. The aforementioned rocks are covered in areas by Tertiary and Quaternary formations. More precisely, the formations of the wider area of study are the following:

- Holocene undivided deposits consisting of sand, gravel, valley deposits and red clay with calcareous concretionary bodies. At the base conglomerates dominate.

- Neogene red clay series with mica and calcareous concretionary bodies.

- Calcareous flysch, known as the Svoula group. It comprises of alternations of detrital or psammitic limestones or ferruginous calcareous sandstones with shales. Olistoliths are intercalated. The above formation's age is bracketed between Triassic to Middle Jurassic.

- Chortiatis magmatic suite, which consists of leucocratic albite-sericite-microcline gneisses, light brown or greenish epigneisses and dark green or brownish greenschists. The above rocks are younger than Upper Triassic and older than the granodiorite of Sithonia type.

The Circum Rhodope belt can be divided in three major units: the Deve Koran - Doumbia unit, the Melissochori - Cholomon unit and the Aspri Vrissi - Chortiatis unit. Two folding events and a greenschist facies metamorphic event have strongly affected the Circum Rhodope belt basement rocks.

The studying area is lying on the Chortiatis magmatic suite. The surface formations consist of a man-made ground in the first few meters and thereafter alluvial deposits, as well as deposits from the erosion of the bedrock. The bedrock is comprised mainly of gneisses, green epigneisses, which are representative of the region of Thessaloniki, and greenschists. 


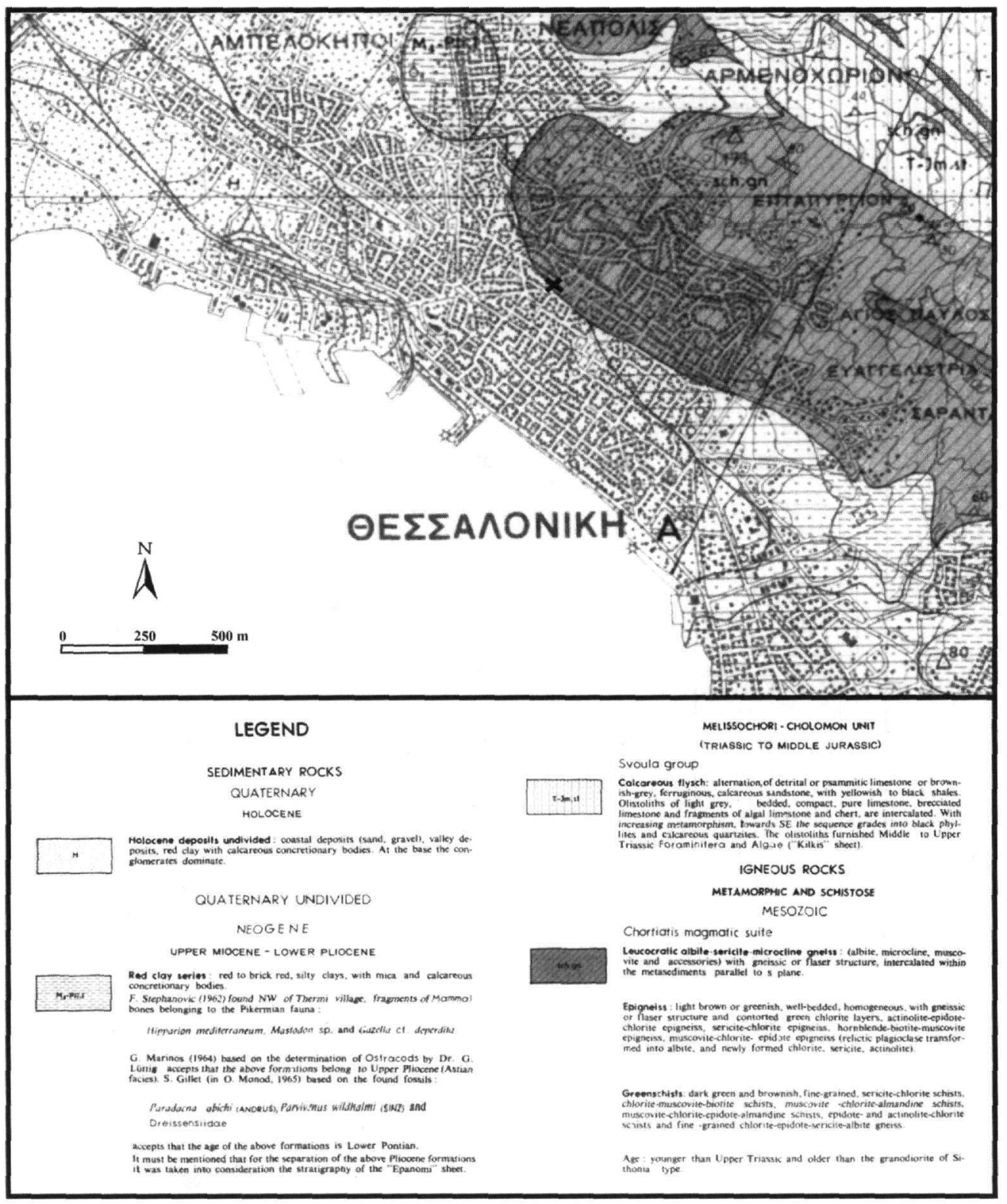

Figure 3 - Abstract of the geological map (IGME 1970). The area of study is depicted with a cross

\section{Data Acquisition and Processing}

The survey involved six parallel sections $\left(2 \_1-2 \_6\right)$ with a northeast-southwest direction and eight parallel sections $\left(1 \_1-1 \_8\right)$ with a northwest-southeast - vertical to the previous - direction (Fig. 4). The sections were spaced $3 \mathrm{~m}$ apart from each other except from section (1_8), which was $1 \mathrm{~m}$ far from section ( 1 7). The dipole-dipole array was measured in some sections, while in others the Wenner array was undertaken. The spacing "a" between electrodes was equal to $1 \mathrm{~m}$ for sections (1_1 - 1_6\&2_1 - 2_5) and equal to $0.75 \mathrm{~m}$ for sections $\left(1 \_7,1 \_8 \& 2 \_6\right)$. The maximum $\mathrm{N}$-separation was $\mathrm{N}_{\max }=8$. The data were collected with the SYSCAL $(\bar{V} 11.4++)$ resistivity meter (IRIS INSTRUMENTS). 


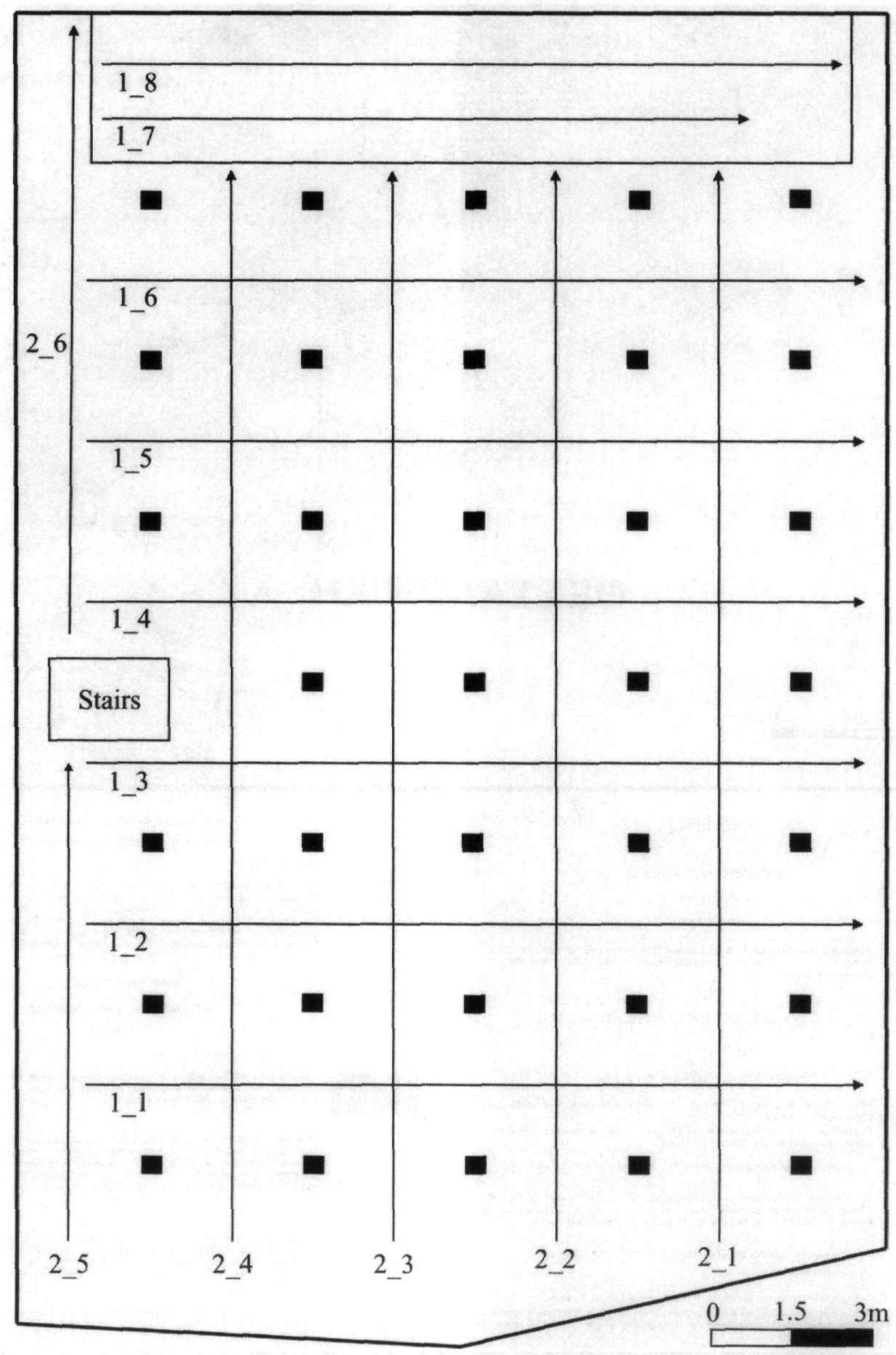

Figure 4 - Sketch of the surveying area, in which the measured sections are shown. (1_1) to (1_8) sections refer to ERT's with northeast-southwest direction, while (2_1) to (2_6) sections refer to ERT's with northwest-southeast direction

The building's basement, where the ERT measurements were carried out, had a $12 \mathrm{~cm}$ thick concrete floor with a resistivity of approximately $300 \mathrm{Ohm}-\mathrm{m}$, whereas its ceiling was leaning on columns with footing-bases of $1 \mathrm{~m}$. The footing-bases are shown in figure (4) as small black squares.

The electrodes used in this survey consist of a square copper flat base (dimensions: $7 \times 7 \mathrm{~cm}$ and thickness of $1 \mathrm{~cm}$ ), which abuts on the surface of the surveying area and a thin cylindric copper segment (length of $7 \mathrm{~cm}$ ) attached to the flat base part to facilitate cable connections (Fig. 5a).

To decrease the contact resistance a conductive gel was applied between the electrodes and the ground (Fig. 5b). This is extremely important since in relatively rough surfaces the somehow 
heavy electrode (more than $1 \mathrm{Kgr}$ ) pressures the gel which fills any open spaces left between the material and the electrode enabling in this way better conduct. The gel used in this work consists of water, salt and low cost cellulose powder (industrial thickener). Alternatively, conductive gel used in medical applications or even confectionery gel can be successfully applied but it is generally more costly. Moreover, it was found that spraying the contact area with salty water prior to the application of the gel helped to further decrease contact resistance (Athanasiou 2004).

2-D resistivity measured data in the form of pseudosections of apparent resistivity produce a distorted image of the subsurface resistivity. Inversion is currently the standard procedure to obtain a realistic estimate of the true resistivity based on the field observations. Among others, the smoothness constraint inversion (Constable et al. 1987) has become the most popular for interpreting ERT data since it produces a simplified subsurface resistivity model which is a reasonable representation of the subsurface and at the same time guarantees inversion stability.

The collected resistivity data were inverted using a flexible non-linear 2-D scheme (Tsourlos 1995, Tsourlos et al. 1998) based on a smoothness constrained algorithm. The aim of the inversion is to construct an estimate of a subsurface resistivity distribution, which is consistent with the experimental data. The algorithm is iterative and fully automated and is based on a reliable $2.5 \mathrm{D}$ finite element forward modeling scheme, which is also used for calculating the Jacobian matrix when necessary. The smoothness inversion scheme, used in this work, tries to calculate a subsurface resistivity estimate $\mathbf{x}$ for which the difference $\mathbf{d y}$ between the observed data and the modeled data (calculated using the forward modeling technique) is minimized under the condition that the roughness of the produced model is minimized. The resistivity correction at the $\mathrm{k}+1$ iteration is given by:

$$
\mathrm{d} \mathbf{x}_{\mathrm{k}+1}=\left[\left(\mathbf{J}_{\mathrm{k}}{ }^{\mathrm{T}} \mathbf{J}_{\mathrm{k}}+\mu \mathbf{C}_{\mathrm{x}}{ }^{\mathrm{T}} \mathbf{C}_{\mathrm{x}}+\mathbf{C}_{\mathrm{z}}{ }^{\mathrm{T}} \mathbf{C}_{\mathrm{z}}\right)\right]^{-1} \mathbf{J}_{\mathrm{k}}{ }^{\mathrm{T}} \mathbf{J}_{\mathrm{k}} \mathrm{d} \mathbf{y}_{\mathbf{k}}
$$

where $\mathrm{Cx}, \mathrm{Cz}$ are matrices which describe the smoothness pattern of the model in the $\mathrm{x}, \mathrm{z}$, directions, $\mathrm{Jk}$ is the Jacobian matrix estimate and $\mu$ is the lagrangian multiplier.
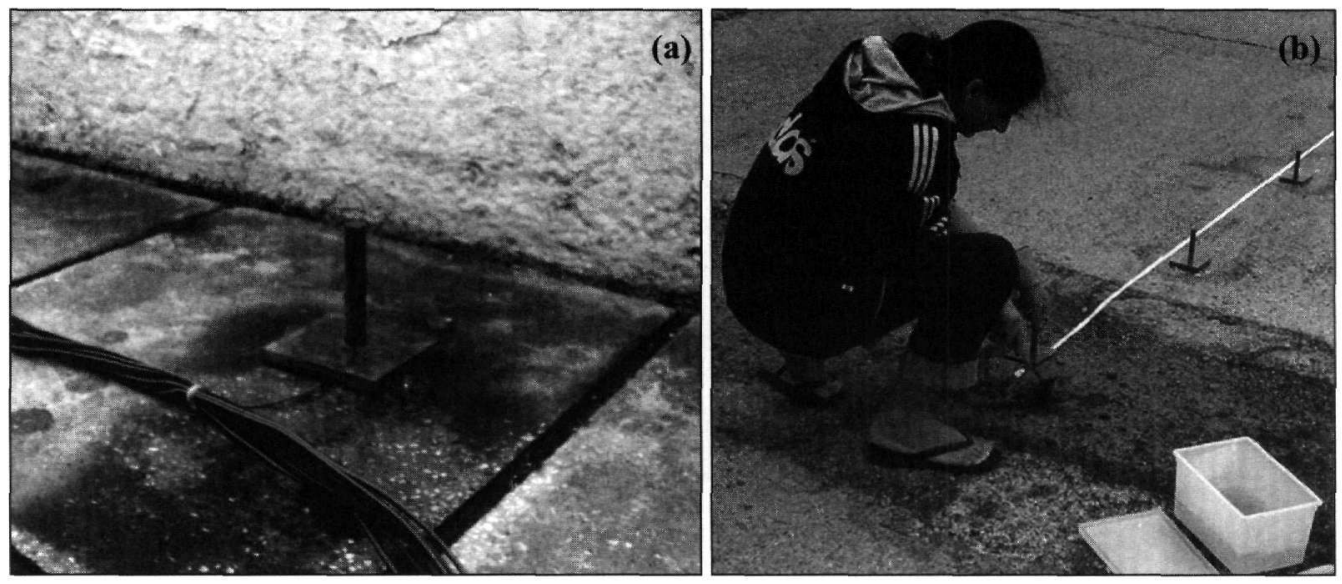

Figure 5 - (a) Flat base electrode used in the field applications, (b) Conductive cellulose gel used to ensure that flat base electrodes are electrically coupled to the surface

A proven 2.5-D Finite Element Method (FEM) scheme was used as the platform for the forward resistivity calculations. In $2.5-\mathrm{D}$ modelling the change in resistivity is considered to be twodimensional but the current flow pattern is a three dimensional one. In other words, the measured values correspond to a three dimensional subsurface where the resistivity is allowed to vary in only two dimensions and remains constant in the strike direction. The adjoin equation approach was incorporated into the FEM scheme in order to calculate the Jacobian matrix $\mathbf{J}$. 

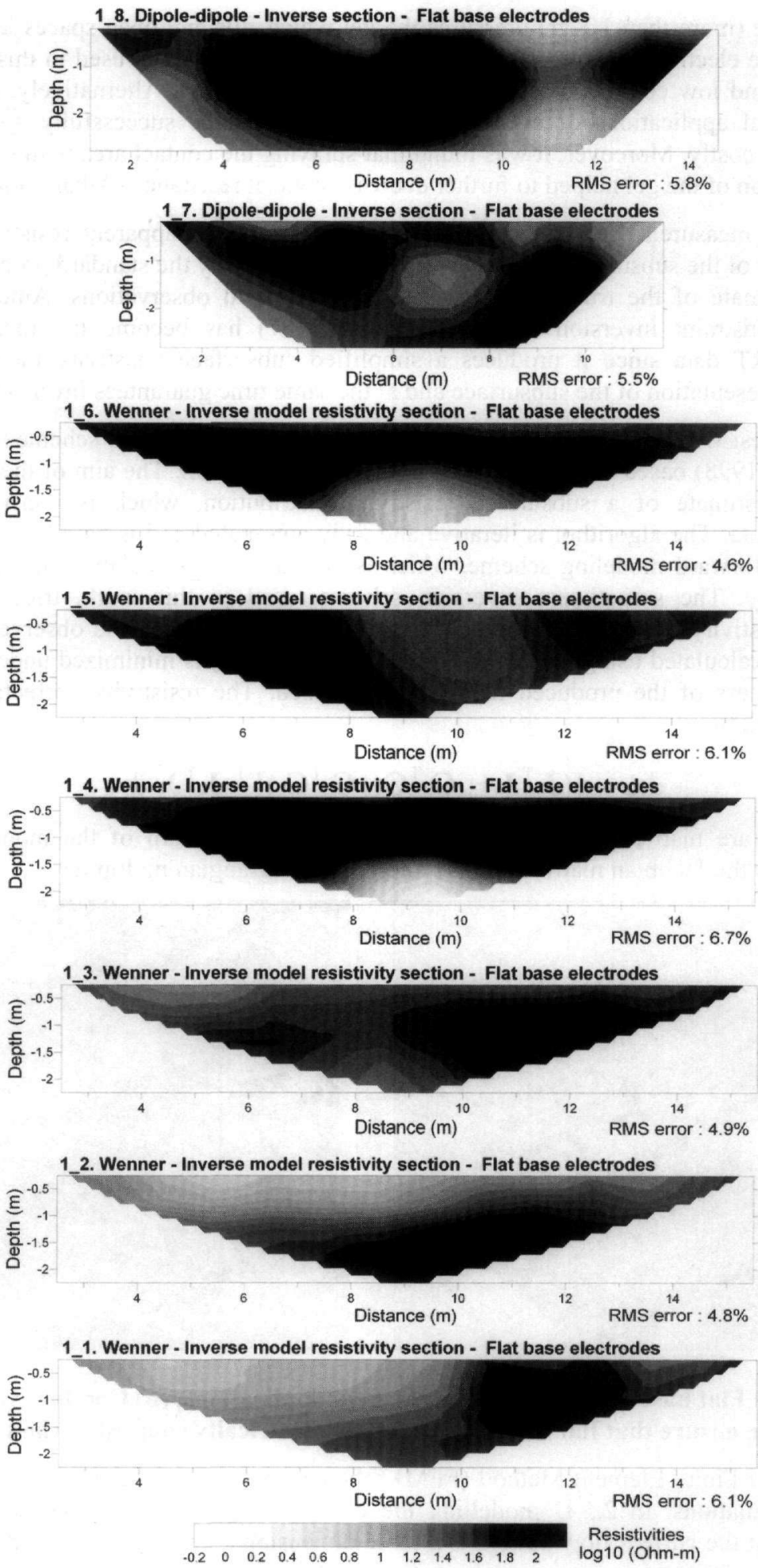

Figure 6 - Geoelectrical inverse model resistivity sections obtained by dipole-dipole and Wenner arrays. These sections have a northwest-southeast direction 


\section{Results and Interpretation}

The inverse model resistivity sections are depicted in figures (6) and (7). The observation of all sections of figure (6) showed the existence of a highly resistive area, which appears in all sections and its center is situated at a distance of approximately $12 \mathrm{~m}$ from the beginning of the tomographies. Also, a second area of high resistivity appears in section (1_3) and continues until section (1_8). Its center is situated at a distance of approximately $6 \mathrm{~m}$ from the beginning of the tomographies. These two resistivity anomalies indicate the existence of linear structures at the area of study.

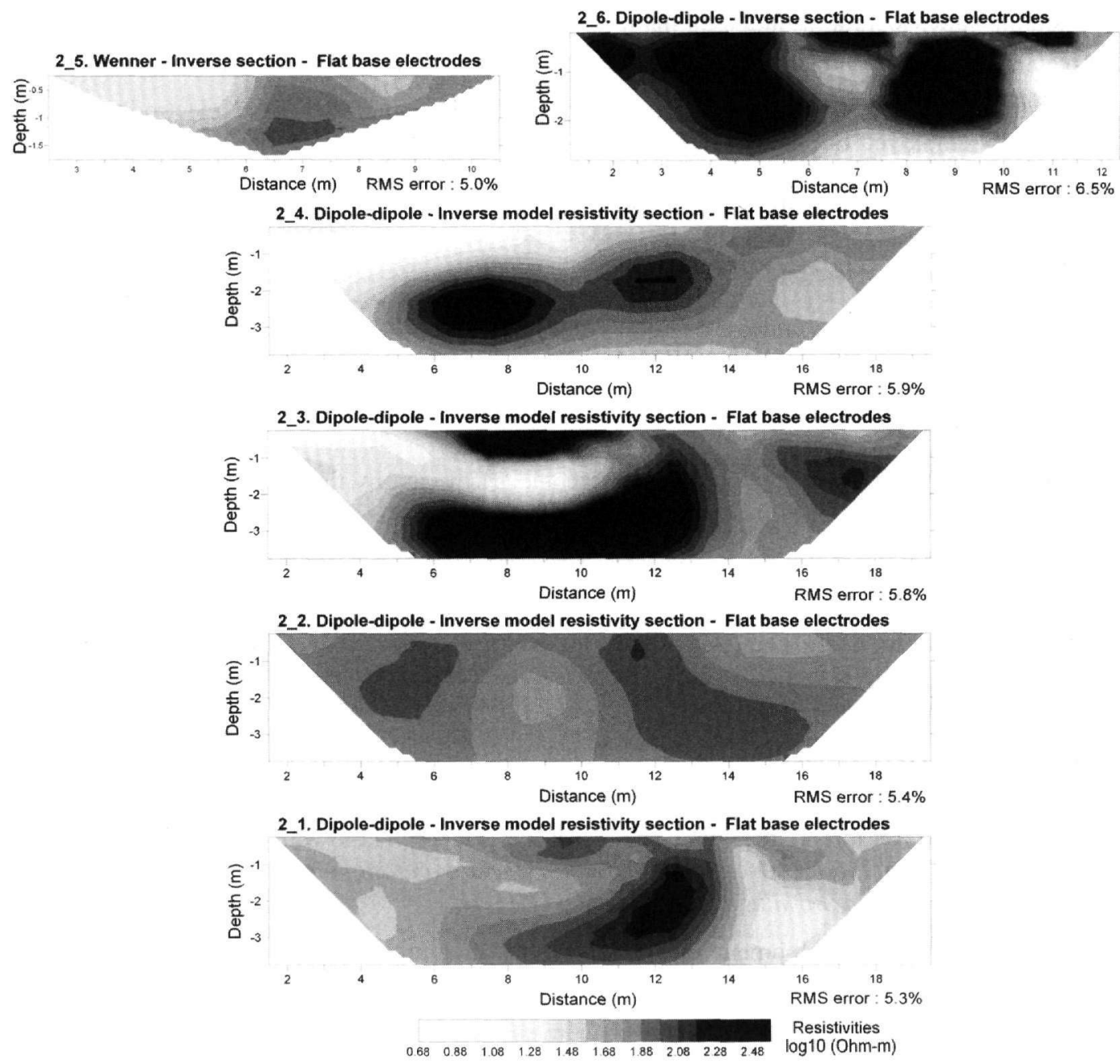

Figure 7 - Geoelectrical inverse model resistivity sections obtained by dipole-dipole and Wenner arrays. These sections have a northeast-southwest direction

The inverted sections of figure (7) are perpendicular to the inverted sections of figure (6). The observation of these sections showed the existence of a high resistive area, which appears in all sections and its center is situated at a distance of approximately $12 \mathrm{~m}$ from the beginning of the tomographies. Also, a second area of high resistivity appears in section (2_2) and continues until section (2_6). Its center is situated at a distance of approximately $7 \mathrm{~m}$ from the beginning of the tomographies. These resistivity anomalies also derive from a subsurface linear structure. 
Due to the fact that the above experiment has been conducted in an environment with a complicated structure, which was aggravated by anthropogenic activity (excavations, embankments, etc.), the linear anomalies may result from various causes. Moreover, the footingbases of the columns are expected to add noise to the already heavy environment.

The linear anomalies of figure (6) may derive from a small scaled linear elevation of the bedrock, due to its intense folding observed in the area of study, or a linear deposition of high resistive alluvial materials. Though, by taking into account the geometry of the anomalies and the outcome of the archaeological excavation on the roadway of Ag. Dimitriou road, it is more possible that the above linear anomalies derive from the continuation of the ancient walls revealed from the archaeological excavation. In line with the last interpretation, the high resistive linear structures of figure (7) may derive from ancient walls perpendicular to the previous ones.

Resistivity measurements performed in this study indicate that flat base electrodes can be satisfactorily employed to map subsurface geoelectrical structures. Using flat base electrodes can extend the applications of geoelectrical techniques in environments that normally resistivity tomography wouldn't be suitable for resistivity tomography.

\section{Acknowledgments}

This work has been funded under a doctoral grant Scholarship to the first of the authors from the Greek State Scholarships Foundation (IKY).

\section{References}

Athanasiou, E., 2004. Combined inversion of geoelectrical data by the use of contact electrodes, M.Sc. Thesis, Aristotle University of Thessaloniki.

Caglar, I., and Duvarci, E., 2001. Geoelectric structure of inland area of Gökova rift, southwest Anatolia and its tectonic implications, Journal of Geodynamics, 31, 33-48.

Carrara, E., Carrozzo, M.T., Fedi, M., Florio, G., Negri, S., Paoletti, V., Paolillo, G., Quarta, T., Rapolla, A., and Roberti, N., 2001. Resistivity and Radar surveys at the Archaeological site of Ercolano, Journal of Environmental and Engineering Geophysics, 6, (3), 123-132.

Constable, S., Parker, R., and Constable, C., 1987. Occam's inversion: A practical algorithm for generating smooth models from electromagnetic sounding data, Geophysics, 52, 289-300.

Cosentino, P., and Martorana, R., 2001. The resistivity grid applied to wall structures: first results, Proceedings of the 7th Meeting of the Environmental and Engineering Geophysical Society, European Section, Birmingham, UK.

Dahlin, T., 2001.The development of DC resistivity imaging techniques, Computers \& Geoscience, 27(9), 1019-1029.

Dahlin, T., and Owen, R., 1998. Geophysical investigations of alluvial aquifers in Zimbabwe, Proceedings of the IV Meeting of the Environmental and Engineering Geophysical Society (European Section), Sept. 1998, Barcelona, Spain, 151-154.

Dahlin, T., Johansson, S. and Landlin, O., 1994. Resistivity surveying for planning of Infrastructure, Published in the Proceedings of SAGEEP, March 27-31, 1994, Boston, Massachusetts, 509-528.

Daniels, D., 2004. Ground Penetrating Radar, 2nd Edition. The IEE, London, UK.

Flathe, H., 1955. Possibilities and limitations in applying geoelectrical methods to hydrogeological problems in the coastal areas of Northwest Germany, Geophysical Prospecting, 3, 95-110.

IGME, 1970. Geological map of Greece, Thessaloniki sheet, scale: 1:50.000. 
Karastathis, V.K., Karmis, P.N., Drakatos, G., and Stavrakakis, G., 2002. Geophysical methods contributing to the testing of concrete dams. Application of the Marathon Dam, Journal of Applied Geophysics, 50, 247-260.

Kauffmann, G., Kockel, F., and Mollat, H., 1976. Notes on the stratigraphic and paleogeographic position of the Svoula Formation in the Innermost Zone of the Hellenides (Northern Greece), Bull. Soc. géol. France, 18,225-230.

Kuras, O., 2002. The Capacitive Resistivity Technique for Electrical Imaging of the Shallow Subsurface, Ph.D. thesis, University of Nottingham.

Papadopoulos, N.G., Tsourlos, P., Tsokas, G.N., and Sarris, A., 2006. Two-dimensional and threedimensional resistivity imaging in archaeological site investigation, Archaeological Propsection, 13(3), 163-181.

Ramirez, A., Daily, W., Binley, A., and Labrecque, D., 1996. Tank leak detection using electrical resistance methods, Symposium on the application of geophysics to engineering and environment, Keystone CO, April 28-May 1, 1996.

Ricou, L.E., Burg, J.P., Godfriaux, I., and Ivanov, Z., 1998. Rhodope and Vardar: The metamorphic and the olistostromic paired belts related to the Cretaceous subduction under Europe, Geodynamica Acta, 11, 285-309.

Rogers, R.B., and Kean, W.F., 1980. Monitoring ground water contamination at a fly ash disposal site using surface resistivity methods, Ground Water, 18, (5), 472-478.

Tsourlos, P., 1995. Modelling interpretation and inversion of multielectrode resistivity survey data, Ph.D. Thesis, University of York.

Tsourlos, P., Szymanski, J., and Tsokas, G., 1998. A smoothness constrained algorithm for the fast 2-D inversion of DC resistivity and induced polarization data, Journal of the Balkan Geophysical Society, 1(1), 3-13.

Van, P.V., Park, S.K., and Hamilton, P., 1991. Monitoring leaks from storage ponds using resistivity methods, Geophysics, 56, 1267-1270.

Wright, P.M., Ward, S.H., Ross, H.P., and West, R.C., 1985. State-of-the-art geophysical exploration for geothermal resources, Geohysics, 50, 2666-2699. 